\title{
Vascular Involvement in Neurosarcoidosis
}

\section{Early Experiences From Intracranial Vessel Wall Imaging}

\author{
Girish Bathla, MBBS, FRCR, MMeD, DABR, Lama Abdel-Wahed, MD, Amit Agarwal, MD, Tracey A. Cho, MD, \\ Sarika Gupta, MD, FRCP, Karra A. Jones, MD, Sarv Priya, MD, Neetu Soni, MD, DNB, and \\ Bruce A. Wasserman, MD
}

Neurol Neuroimmunol Neuroinflamm 2021;8:e1063. doi:10.1212/NXI.0000000000001063

\section{Abstract}

\section{Background and Objectives}

Cerebrovascular manifestations in neurosarcoidosis (NS) were previously considered rare but are being increasingly recognized. We report our preliminary experience in patients with NS who underwent high-resolution vessel wall imaging (VWI).

\section{Methods}

A total of 13 consecutive patients with NS underwent VWI. Images were analyzed by 2 neuroradiologists in consensus. The assessment included segment-wise evaluation of largerand medium-sized vessels (internal carotid artery, M1-M3 middle cerebral artery; A1-A3 anterior cerebral artery; V4 segments of vertebral arteries; basilar artery; and P1-P3 posterior cerebral artery), lenticulostriate perforator vessels, and medullary and deep cerebral veins. Cortical veins were not assessed due to flow-related artifacts. Brain biopsy findings were available in 6 cases and were also reviewed.

\section{Results}

Mean patient age was 54.9 years (33-71 years) with an M:F of 8:5. Mean duration between initial diagnosis and VWI study was 18 months. Overall, 9/13 (69\%) patients had vascular abnormalities. Circumferential large vessel enhancement was seen in 3/13 (23\%) patients, whereas perforator vessel involvement was seen in 6/13 (46\%) patients. Medullary and deep vein involvement was also seen in 6/13 patients. In addition, 7/13 (54\%) patients had microhemorrhages in susceptibility-weighted imaging, and 4/13 (31\%) had chronic infarcts. On biopsy, 5/6 cases showed perivascular granulomas with vessel wall involvement in all 5 cases.

\section{Discussion}

Our preliminary findings suggest that involvement of intracranial vascular structures may be a common finding in patients with NS and should be routinely looked for. These findings appear concordant with previously reported autopsy literature and need to be validated on a larger scale.

\footnotetext{
From the Department of Radiology (G.B., S.P., N.S.), University of lowa Hospitals and Clinics; Department of Neurology (L.A.-W., T.A.C.), University of Iowa Hospitals and Clinics, IA; Department of Radiology (A.A.), University of Texas Southwestern Medical Center; Department Pathology (S.G., K.A.J.), University of lowa Hospitals and Clinics, IA; and Department of Radiology (B.A.W.), Johns Hopkins School of Medicine, Baltimore, MD.

Go to Neurology.org/NN for full disclosures. Funding information is provided at the end of the article. 


\section{Glossary}

$\mathbf{A Z A}=$ azathioprine $; \mathbf{C A D}=$ coronary artery disease $\mathbf{C N E}=$ cranial nerve enhancement $; \mathbf{D M}-2=$ type 2 diabetes; $\mathbf{D W I}=$ diffusion-weighted imaging; $\mathbf{E E}=$ ependymal enhancement; FLAIR = fluid-attenuated inversion recovery; $\mathbf{H C}=$ hydrocephalus; HL = hyperlipidemia; HT = hypertension; INX = infliximab; LME = leptomeningeal enhancement; LSP = lenticulostriate perforator; MMF = mycophenolate mofetil; MinIP = minimum intensity projection; $\mathbf{M T X}=$ methotrexate; NEWM = nonenhancing white matter; NS = neurosarcoidosis; NT = not tested; PGE = parenchymal granulomatous enhancement; PME = pachymeningeal enhancement; PVE = perivascular enhancement; $\mathbf{R T X}=$ rituximab; SPACE = sampling perfection with application-optimized contrasts using different flip angle evolution; SWI = susceptibility-weighted imaging; VWI = vessel wall imaging; FSR = Foundation of Sarcoidosis Research .

Sarcoidosis is an inflammatory, granulomatous disease that most commonly affects the lungs followed by lymph nodes and skin. ${ }^{1-3}$ Involvement of the CNS referred to as neurosarcoidosis (NS) is seen in about $5 \%$ of sarcoid patients with neurologic manifestations and about $15 \%$ of patients on imaging. ${ }^{2,4}$ Although common manifestations of NS such as meningitis, cranial nerve enhancement, parenchymal granulomatous involvement, and nonenhancing white matter (NEWM) lesions have been frequently reported, both the clinical and imaging manifestations of cerebrovascular involvement have remained less well described. ${ }^{1,4,5}$ Traditionally, these were felt to be present in $1 \%-2 \%$ of patients with NS. ${ }^{6-8}$ This was likely an underrepresentation secondary to multiple contributory factors such as absence of more sensitive, high-resolution sequences and absence of dedicated imaging review. ${ }^{4,5,9}$ More recently, involvement of the medullary veins on susceptibility-weighted imaging (SWI) and a relatively high proportion of cerebral infarcts (presumably secondary to underlying vasculitic/vasculopathic process) have been described and raise important questions about the extent and distribution of vascular involvement in patients with NS. ${ }^{9,10}$ Herein, we describe our preliminary findings of high-resolution black-blood imaging, also referred to as vessel wall imaging (VWI) in a series of 13 patients with NS.

\section{Methods}

\section{Standard Protocol Approvals, Registrations, and Patient Consents}

This is a retrospective, institutional review board-approved study performed in a tertiary care setting. Some of the patients were scanned as part of another ongoing prospective study sponsored by the Foundation of Sarcoidosis Research (FSR) and were consented for the study. In patients who were not involved in the FSR study, individual consent was waived for the retrospective analysis by the local institutional review board.

\section{Patient Selection}

There were a total of 13 consecutive patients with NS who underwent VWI between July 2018 and June 2020. Because recent studies have shown a higher prevalence of cerebrovascular events in NS, ${ }^{4,9}$ our institutional protocol was modified to include VWI in all patients with NS. None of the imaged patients in the current cohort, however, were imaged for suspected vasculitis or infarct. Of the patients who underwent imaging, 5 patients had definite NS, 6 had probable NS, and 2 had possible NS, both as defined under the Zajicek criteria and the recently proposed criteria by the NS consortium consensus group. $^{11,12}$ Regardless of the category (definite, probable, or possible), the clinical presentation and diagnostic evaluation must be suggestive of NS, as defined by the clinical manifestations and MRI, CSF, and/or nerve conduction study findings typical of granulomatous nervous system inflammation along with rigorous exclusion of other causes. ${ }^{12}$ In addition, patients with definite NS must have neural tissue pathologic confirmation of granulomatous inflammation, whereas those in the probable category require pathologic confirmation of systemic granulomatous disease. Patients categorized as possible NS do not have pathologic tissue diagnosis, but the clinical and diagnostic evaluation is suggestive of NS.

\section{Data Acquisition and Analysis}

All patients were scanned on a $3 \mathrm{~T}$ magnet using a uniform protocol consisting of 3D T1W SPACE (sampling perfection with application-optimized contrasts using different flip angle evolution) sequence obtained pre- and post-contrast (in sagittal orientation), 3D T2W SPACE through the basal ganglia region, 3D fluid-attenuated inversion recovery (FLAIR), axial SWI, and diffusion-weighted imaging (DWI). The isotropic VWI was obtained at a voxel size of $0.63 \mathrm{~mm}^{3}$. The sequence parameters for all sequences are provided in eFigure 1, links.lww.com/NXI/A542.

The acquired data were analyzed by 2 staff neuroradiologists in consensus using a prespecified template for data collection. Data were collected separately for large arterial vessels, arterial perforators, medullary veins, and caudate veins. Data on larger vessels (defined as supraclinoid internal carotid artery, A1-A3 anterior cerebral artery, M1-M3 middle cerebral artery, vertebral and basilar arteries, and P1-P3 posterior cerebral artery) included a segment-wise analysis of wall enhancement characteristics. Atherosclerotic involvement of intracranial vessels is generally more eccentric and more common at branch points. Vasculitic or inflammatory involvement, on the other hand, is more likely to be circumferential. ${ }^{13}$ For the current study, vascular involvement was considered to be present when there was circumferential wall enhancement or obvious involvement of the vessel wall by extravascular enhancement. 
Arterial perforators were categorized as abnormal if they were visibly tortuous or reached up to the subependymal region. Only the lenticulostriate perforator vessels were assessed because these are within the resolution limits of clinical VWI sequences. Perivascular enhancement (PVE) was defined as the presence of linear intraparenchymal enhancement either along a lumen or along the expected course of an arterial/ venous structure. Medullary veins were categorized as abnormal if they were tortuous and visibly abnormal on both $\mathrm{T} 1$ WI and SWIs. The assessment of the cortical and deep veins was technically the most challenging because these may show enhancement secondary to slow flow and a higher proportion of vasa vasorum in the vessel wall. ${ }^{14,15}$ These were therefore not included in the analysis. Nonvascular manifestations of NS, such as meningeal enhancement, NEWM lesions, cranial nerve involvement, ependymal and pituitary involvement and hydrocephalus, were also assessed, both on the VWI-MRI and the initial standard MRI at the time of diagnosis.

In addition, data were collected on the time between initial diagnosis and VWI-MRI and overall clinical status since diagnosis (improved, stable, or worse). Additional data on cardiovascular risk factors at the time of initial diagnosis (diabetes, smoking, hypercholesterolemia, and hypertension) were also collected. In patients who had a brain biopsy available, the pathologic findings were reviewed by a neuropathologist for vascular involvement. Because the purpose of the study was to evaluate the spectrum of imaging findings in patients with NS, only descriptive statistics were used.

\section{Data Availability}

The anonymized data will be shared by the lead author on request from any qualified investigator.

\section{Results}

The 13 patients included 8 men and 5 women with a mean age of 54.9 years at presentation (range 33-71 years, SD 13 years). The median time interval between the presentation and the VWI study was 18 months (range: 10 days- 83 months). Seven patients had concomitant pulmonary involvement. All patients had evidence of systemic disease, except for 2 patients who had isolated CNS involvement. Table 1 lists the presenting symptoms/signs as well as the CSF findings, treatment, and clinical status between presentation and time of VWI study. Nine patients showed clinical improvement, whereas 2 were stable and 1 was worse between the initial diagnosis and time of VWI study. The mean number of cardiovascular risk factors was 1.3 per patient, with hypertension being the most common, seen in $9 / 13$ patients.

In terms of vascular involvement, $3 / 13$ patients showed evidence of large vessel involvement. The involvement was circumferential in 2 patients and secondary to involvement by the surrounding meningeal process in 1 patient (Figure 1). Involvement of the lenticulostriate perforators was seen in 6/ 13 patients, generally manifesting as dilated or tortuous vessels (Figure 2). The involvement was unilateral in 2 patients and bilateral in $4 / 6$ patients.

Tortuous and prominent medullary veins were noted in 5/13 patients (Figure 3). These were often asymmetrically involved both in terms of number of dilated vessels and prominence. Involvement of the medullary veins was most frequently seen in the frontal and parietal regions, although similar findings in the temporal lobes were also noted in a few patients. Similarly, involvement of the longitudinal and transverse caudate veins was seen in 6/13 patients and was present in all patients who had involvement of the medullary veins. In total, there were 9 patients who had some form of vascular involvement, either arterial or venous, on the VWI study.

Besides the vascular findings, microhemorrhages were present in $7 / 13$ patients, including all 6 patients with parenchymal venous involvement. Chronic infarcts were noted in $4 / 13$ patients. There were no patients with acute infarcts at the time of the VWI study. eTable 2, links.lww.com/NXI/A543, shows the frequency of various imaging findings at initial presentation and at the time of VWI study. The apparent increase in PVE despite therapy and clinical improvement is likely due to the high imaging resolution (slice thickness of $0.6 \mathrm{~mm}$ on VWI study compared with $5 \mathrm{~mm}$ on index study), leading to improved recognition. Leptomeningeal involvement, dural involvement, and cranial nerve enhancement were more likely to show improvement with therapy. NEWM lesions on the other hand showed slight interval worsening during the same time period. Table 2 shows the imaging findings in individual patients at the time of initial diagnosis as well as the vascular findings on the subsequent MRI study. When treating all imaging manifestations (e.g., NEWM and PVE) as binary variables (present/absent), patients with positive VWI findings tended to have more imaging manifestations (4/patient) compared with those without any VWI findings (2.2/patient, Table 2). However, we did not find any significant differences between individual imaging manifestations between those with and without VWI findings.

Of the 6 patients whose brain biopsy slides were reviewed, 5 had non-necrotizing granulomatous inflammation, whereas 1 showed lymphoplasmacytic inflammation with scattered histiocytes. Granulomas were seen in a perivascular distribution with heterogeneous vessel wall involvement that ranged from partial to transmural without evidence of fibrinoid necrosis of the vessel walls. Four patients had arteriolar wall involvement, whereas 1 patient had both arteriolar and peri-venular involvement (eFigure 1, links.lww.com/NXI/A542; eTable 3, links.lww.com/NXI/A543). There was no evidence of betaamyloid deposition within vessel walls.

\section{Discussion}

Vascular manifestations in NS are likely more common than previously reported. These may involve both large and smaller 
Table 1 Patient Demographics, Presentations, CSF Analysis, Treatment Summary, and Clinical Outcomes of the Patients With Vessel Wall Imaging

\begin{tabular}{|c|c|c|c|c|c|c|c|c|c|}
\hline & $\begin{array}{l}\text { Age (yrs) } \\
\text { at onset } \\
\text { and sex }\end{array}$ & Presenting signs and symptoms & $\begin{array}{l}\text { Associated neurologic } \\
\text { symptoms }\end{array}$ & Relevant history & $\begin{array}{l}\text { CSF total } \\
\text { nucleated } \\
\text { cells } \\
\text { (differential) }\end{array}$ & $\begin{array}{l}\text { CSF } \\
\text { protein/ } \\
\text { glucose }\end{array}$ & $\begin{array}{l}\text { Biopsy } \\
\text { site }\end{array}$ & Treatment & $\begin{array}{l}\text { Clinical } \\
\text { outcome }\end{array}$ \\
\hline P01 & $48 / F$ & $\begin{array}{l}\text { Parenchymal hemorrhages, } \\
\text { seizures, meningitis, and HPA axis } \\
\text { involvement (diabetes insipidus) }\end{array}$ & $\begin{array}{l}\text { Encephalopathy, headache, and } \\
\text { syncope }\end{array}$ & $\mathrm{HL}$ & 65 (lymphs) & $219 / 31$ & Brain & Steroid taper then MTX & Improved \\
\hline P02 & $61 / F$ & Cranial neuropathies & Vertigo, ptosis, and dysarthria & $\begin{array}{l}\mathrm{DM}-2, \mathrm{HT}, \mathrm{HL}, \mathrm{CAD} \text {, migraine } \\
\text { headache, and history of } \\
\text { endometrial cancer }\end{array}$ & NT & NT/NT & $\begin{array}{l}\text { Lymph } \\
\text { node }\end{array}$ & $\begin{array}{l}\text { Steroid taper } \\
\text { Trials of } \\
\text { MTX-leflunomide-hydroxychloroquine-MMF }\end{array}$ & Improved \\
\hline P03 & $55 / F$ & $\begin{array}{l}\text { Parenchymal lesions and cranial } \\
\text { neuropathies }\end{array}$ & $\begin{array}{l}\text { Aphasia, hemiparesis, and } \\
\text { encephalopathy }\end{array}$ & DM-2 and HT & $\begin{array}{l}8 \text { (traumatic } \\
\text { puncture) }\end{array}$ & $65 / 54$ & Brain & $\begin{array}{l}\text { Steroid taper (weaned) } \\
\text { MTX + INX (ongoing) }\end{array}$ & Improved \\
\hline P04 & $71 / F$ & Meningitis and vasculitis & $\begin{array}{l}\text { Headache, ischemic stroke, and } \\
\text { paraparesis }\end{array}$ & $\begin{array}{l}\mathrm{HT} \text {, history of enterovirus } \\
\text { meningitis }\end{array}$ & 26 (lymphs) & $82 / 69$ & $\begin{array}{l}\text { Skin } \\
\text { and } \\
\text { brain }\end{array}$ & $\begin{array}{l}\text { High-dose steroids for } 5 \mathrm{~d} \text {. } \\
\text { Trials of RTX-MMF (stopped due to side effects) }\end{array}$ & Improved \\
\hline P05 & $66 / M$ & $\begin{array}{l}\text { Myelopathy, brainstem syndrome, } \\
\text { and meningitis }\end{array}$ & $\begin{array}{l}\text { Diplopia, vertigo, gait } \\
\text { disturbance, and } \\
\text { encephalopathy }\end{array}$ & HT & 29 (lymphs) & $114 / 68$ & Brain & $\begin{array}{l}\text { Steroid taper (weaned) } \\
\text { MTX + INX (ongoing) }\end{array}$ & Improved \\
\hline P06 & $71 / \mathrm{M}$ & Cystic mass lesion & $\begin{array}{l}\text { Headache and visual field } \\
\text { deficits }\end{array}$ & $\mathrm{HT}, \mathrm{HL}$, and glaucoma & NT & NT/NT & Brain & Steroid taper & Stable \\
\hline P07 & $60 / M$ & Myelopathy & Hemiparesthesias and neck pain & $\begin{array}{l}\mathrm{DM}-2, \mathrm{HT}, \mathrm{HL}, \mathrm{CAD} \text {, history } \\
\text { of gastric cancer, and DVT/ } \\
\mathrm{PE}\end{array}$ & 21 (lymphs) & $94 / 78$ & $\begin{array}{l}\text { Spinal } \\
\text { cord }\end{array}$ & Steroid taper & Declined \\
\hline P08 & $48 / \mathrm{M}$ & Cranial neuropathies & Headache and diplopia & HT & 3 (lymphs) & $37 / 73$ & $\begin{array}{l}\text { Lymph } \\
\text { node }\end{array}$ & Steroid taper (weaned) & Improved \\
\hline P09 & $34 / \mathrm{M}$ & $\begin{array}{l}\text { Parenchymal hemorrhages, } \\
\text { cerebellar syndrome, and meningitis }\end{array}$ & $\begin{array}{l}\text { Headache, dizziness, vomiting, } \\
\text { paresthesia, and presyncope }\end{array}$ & Crohn disease & 68 (lymph) & $95 / 50$ & $\begin{array}{l}\text { Lymph } \\
\text { node }\end{array}$ & Already on steroids and vedolizumab for Crohn & Improved \\
\hline P10 & $42 / \mathrm{M}$ & Pachymeningitis & Headache & - & 1 & $17 / 65$ & Brain & None & Improved \\
\hline P11 & $68 / F$ & Cranial neuropathies and meningitis & $\begin{array}{l}\text { Diplopia, vertigo, gait } \\
\text { disturbance, and paresthesias }\end{array}$ & HT & 50 (histiocytes) & $116 / 22$ & None & INX & Stable \\
\hline P12 & $57 / M$ & $\begin{array}{l}\text { Cranial neuropathies and basal } \\
\text { meningitis }\end{array}$ & $\begin{array}{l}\text { Hearing loss, vertigo, gait } \\
\text { disturbance, paresthesias, and } \\
\text { choreoathetotic movements }\end{array}$ & DM-2 and HT & 35 (lymphs) & $107 / 23$ & Lung & $\begin{array}{l}\text { Steroid taper (weaned) } \\
\text { AZA + INX (ongoing) }\end{array}$ & Stable \\
\hline P13 & $33 / \mathrm{M}$ & Meningitis & $\begin{array}{l}\text { Headache, vertigo, vomiting, and } \\
\text { encephalopathy }\end{array}$ & - & $\begin{array}{l}\text { High with } \\
\text { lymphs (value } \\
\text { not available) }\end{array}$ & $\begin{array}{l}\text { High/low } \\
\text { (value not } \\
\text { available) }\end{array}$ & $\begin{array}{l}\text { Lymph } \\
\text { node }\end{array}$ & $\begin{array}{l}\text { Steroid taper (ongoing) } \\
\text { Trial of INX (stopped due to transaminitis) }\end{array}$ & Improved \\
\hline
\end{tabular}

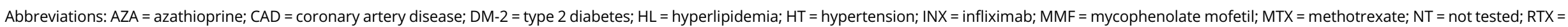
rituximab. 
Figure 1 Large Vessel Involvement in Neurosarcoidosis
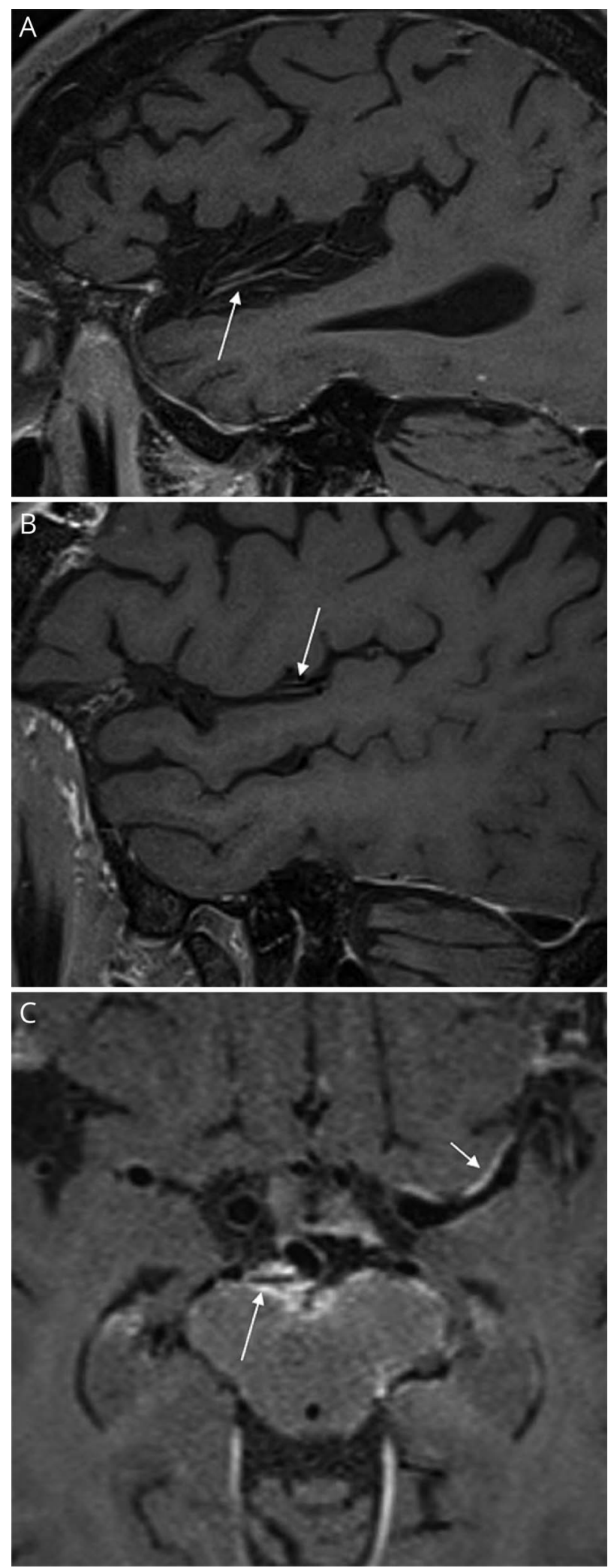

Postcontrast T1W sagittal images (A and $\mathrm{B}$ ) and axial multiplanar reconstruction vessel wall image (C) from 3 different patients (P04, 05, and P12, respectively) showing enhancement of the right middle cerebral artery (arrows in A and B), as well as the left middle cerebral artery (short arrow in C), right basilar tip and posterior cerebral artery (arrow in C). vessels and may result from primary vascular involvement or occur secondarily to involvement of surrounding structures. Although our study noted various imaging findings suggestive of vascular involvement, it is noteworthy that most of these studies were performed on patients who were already on treatment and clinically improved. That patients with positive VWI findings tended to have more imaging abnormalities overall may imply that these patients have more extensive disease. It is also possible that the prevalence of vascular involvement may be even higher in patients with NS who are treatment naive.

Involvement of the larger intracranial internal carotid artery vessels is generally considered rare and may not translate into ischemic strokes. ${ }^{5}$ As such, the occurrence of lacunar strokes is much more common in NS compared with territorial infarcts. ${ }^{4,5,16,17}$ As noted in P12, large vessel involvement may also be seen with leptomeningitis secondarily involving the vessel wall. In our cases with vessel wall enhancement, there was no intraluminal thrombus, significant stenosis, or presence of larger infarcts in the involved vascular territory. This may also help explain why thrombotic complications with large vessel involvement are not common in NS.

Arterial perforator involvement at the level of basal ganglia was relatively common in our cohort. Unlike patients with small vessel disease related to stroke or chronic hypertension, we noted increased tortuosity of the perforator vessels. ${ }^{18,19}$ Tortuous lenticulostriate perforators may be seen with increasing age or in patients with subcortical vascular dementia. ${ }^{20,21}$ However, the involvement of perforator vessels was seen in about $46 \%(6 / 13)$ of our patients and is therefore unlikely to be a chance finding or simply related to age. It is pertinent to point here that one of these patients had a lacunar infarct, whereas another had a microhemorrhage in the basal ganglia region.

Involvement of the medullary veins was seen in 38\% of cases. This is similar to the previously reported prevalence of medullary venous involvement of about $33 \%$ in NS. ${ }^{10}$ In all cases, findings were seen both on VWI-MRI and SWI, with the findings appearing more apparent on the SWI sequences. It is possible that SWI findings may reflect both a combination of slow flow and underlying vascular tortuosity secondary to wall involvement. Because the T1 SPACE primarily captures the anatomic distortion/tortuosity and not the contributory effect of deoxygenated blood or slow flow, it likely only reflects part of the underlying pathologic process. It is therefore possible that the T1WI images likely only reflect the permanent vessel injury. Nevertheless, the discordance between the SWI and T1-SPACE images may be relevant in terms of underlying pathophysiologic effects and needs to be compared against age-matched healthy controls to better define their clinical relevance.

All cases with medullary venous involvement showed parenchymal microhemorrhages to a variable degree, often in the 

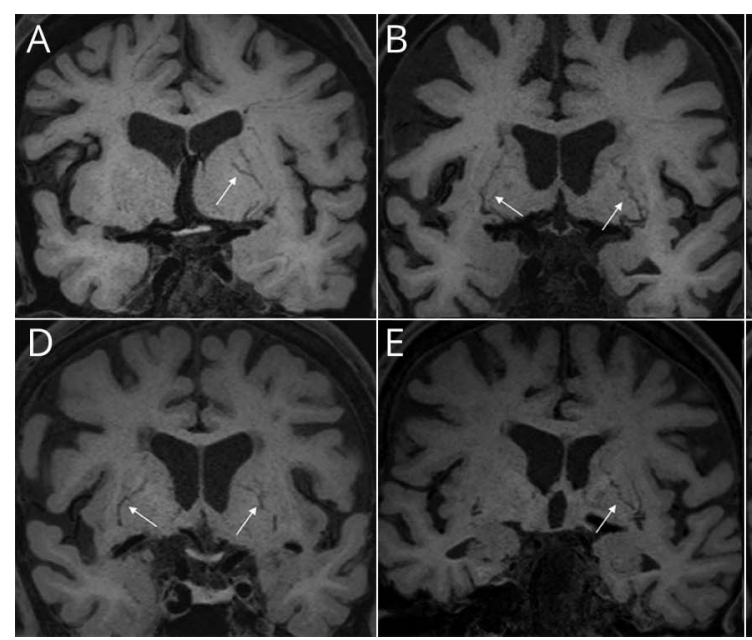

Coronal 3-mm minimum intensity projection T1W images (A-F) at the level of basal ganglia from 6 different patients (P01, 05, 09, and P12-14) show both unilateral $(A, C$, and $E$ ) and bilateral $(B, D$, and F) involvement of the perforator vessels (white arrows). Small white arrow in panel C shows a dilated medullary vein. same region as the venous findings on SWI suggesting that the underlying venous involvement could be contributing to the microhemorrhages. Besides NS, engorged medullary veins may also be seen with dural sinus thrombosis or fistula. A prior study noted mild paucity of cortical veins in patients with NS, although the difference was not statistically significant. ${ }^{10}$ However, they used postcontrast magnetization-prepared rapid acquisition with gradient echo images for assessment of the cortical veins. Because our study used a different imaging sequence, the cortical veins could not be assessed.
Involvement of the longitudinal and transverse caudate veins tended to follow a similar distribution and was seen in all patients with medullary venous involvement. In addition, 1 patient had isolated involvement of the caudate veins. Imaging assessment of the deep cerebral veins, sagittal sinuses, and cortical veins was, however, more technically complicated, partly due to a component of physiologic variability in venous anatomy and partly due to flow artifacts from slow flow. Although some patients with parenchymal venous involvement had prominent signal along the cortical veins, underlying flow
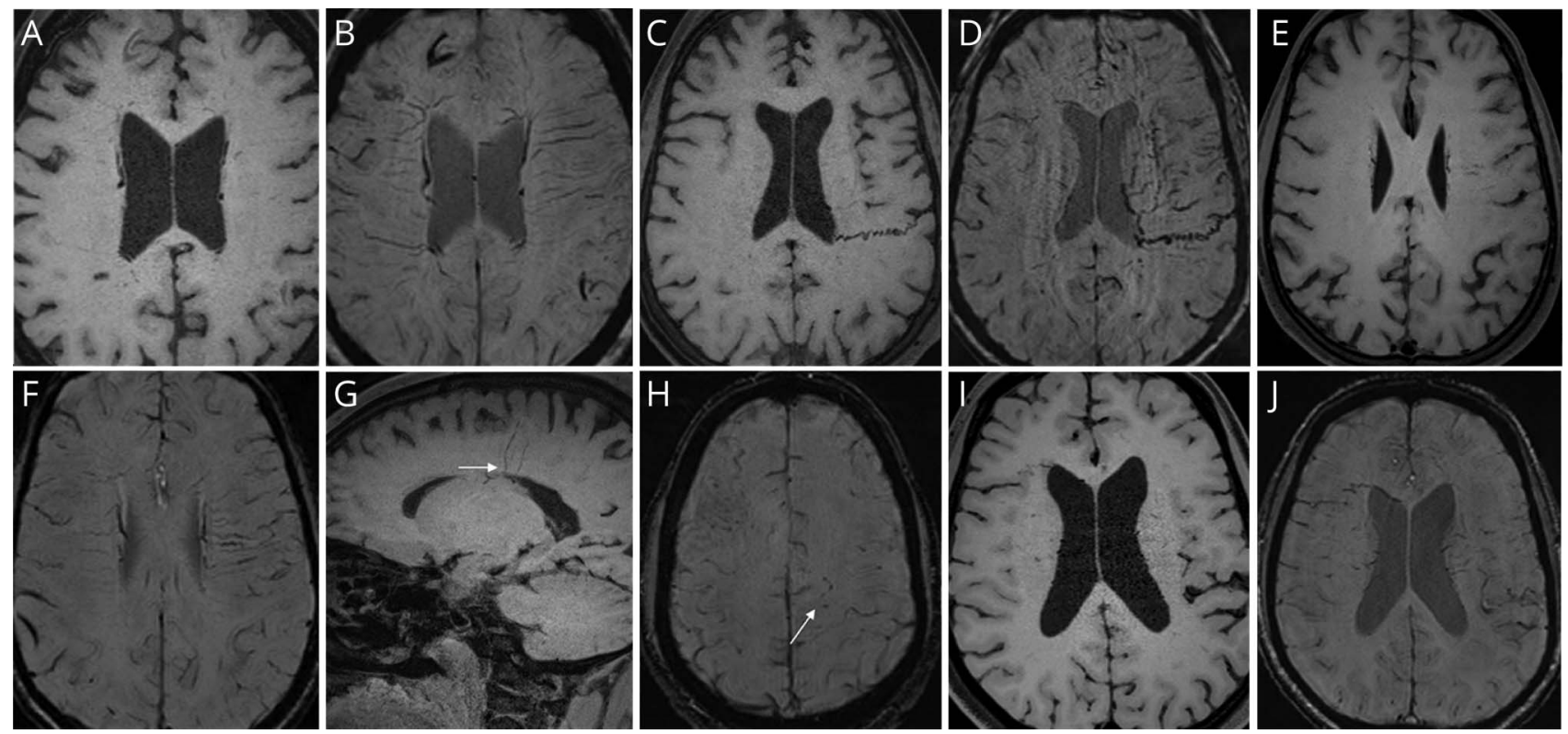

AxialT1W (A, C, E, and I) and sagittal (G) 2.4-mm MinIP T1W images with corresponding SWI images (B, D, F, H, and J) from the same patients (P01, 03, 09, 11, and 14). There is dilatation of medullary veins, which can be both symmetric and asymmetric. This is visible on both the T1W and SWls but is more conspicuous on the latter. Vertically oriented veins in panel G (white arrow) correspond to the white arrow panel H. MinIP = minimum intensity projection; SWI = susceptibility-weighted imaging. 
Table 2 Imaging Findings at Presentation and VWI Findings at Follow-up Study for All Patients With Neurosarcoidosis

\begin{tabular}{|c|c|c|c|c|c|c|c|}
\hline \multirow[b]{2}{*}{$\begin{array}{l}\text { Patient } \\
\text { ID }\end{array}$} & \multirow[b]{2}{*}{$\begin{array}{l}\text { Conventional imaging } \\
\text { findings at presentation }\end{array}$} & \multicolumn{6}{|c|}{ VWI findings on follow-up MRI } \\
\hline & & $\begin{array}{l}\text { Large vessel } \\
\text { involvement }\end{array}$ & $\begin{array}{l}\text { LSP } \\
\text { involvement }\end{array}$ & $\begin{array}{l}\text { Medullary vein } \\
\text { involvement }\end{array}$ & $\begin{array}{l}\text { Caudate vein } \\
\text { involvement }\end{array}$ & Microhemorrhages & $\begin{array}{l}\text { Chronic } \\
\text { infarcts }\end{array}$ \\
\hline P01 & HPA, CNE, LME, and EE & - & + & + & + & + & - \\
\hline P02 & NEWM and CNE & - & - & - & - & - & - \\
\hline P03 & $\begin{array}{l}\text { PGE, PVE, NEWM, CNE, LME, } \\
\text { and PME }\end{array}$ & - & - & + & + & + & - \\
\hline P04 & PGE, NEWM, CNE, and LME & + & - & - & - & + & + \\
\hline P05 & PGE, PVE, NEWM, and EE & + & + & - & - & + & + \\
\hline P06 & NEWM and LME & - & - & - & - & - & + \\
\hline P07 & NEWM, EE, LME, and PME & - & - & - & - & + & - \\
\hline P08 & PME & - & - & - & - & - & - \\
\hline P09 & $\mathrm{EE}, \mathrm{CNE}$, and LME & - & + & + & + & + & - \\
\hline P10 & LME and PME & - & - & + & + & - & - \\
\hline P11 & NEWM, CNE, and LME & + & + & - & + & + & - \\
\hline P12 & NEWM, CNE, and LME & - & + & - & - & - & - \\
\hline P13 & $\begin{array}{l}\text { NEWM, HPA, EE, LME, CNE, } \\
\text { PME, and HC }\end{array}$ & - & + & + & + & - & + \\
\hline
\end{tabular}

Abbreviations: + /- = present/absent; $\mathrm{CNE}=$ cranial nerve enhancement; $\mathrm{EE}=$ ependymal enhancement; $\mathrm{HC}=$ hydrocephalus; $\mathrm{LME}=$ leptomeningeal enhancement; LSP = lenticulostriate perforator; NEWM = nonenhancing white matter; PGE = parenchymal granulomatous enhancement; PME = pachymeningeal enhancement; PVE = perivascular enhancement; $\mathrm{VWI}=$ vessel wall imaging.

artifact or anatomical variation could not be excluded with certainty. Their assessment was therefore not included in the analysis.

Our study, although performed on a small patient cohort, provides insights into the spectrum of vascular involvement in patients with NS using dedicated VWI-MRI. Our findings support prior observations that cerebrovascular manifestations are likely more common than previously realized and involve both arterial and venous structures, similar to primary angiitis of the CNS., This is also supported by the review of brain histopathology slides, which were available in 6/13 patients with NS.

Our findings are also concordant with previously reported autopsy literature. Delaney et al., ${ }^{22}$ for example, reviewed brain autopsy cases in 14 patients with NS and noted subclinical infarctions in 9 cases. Presence of infarcts and hemorrhage on autopsy studies in NS has also been reported in multiple prior case reports. ${ }^{5,7,23}$ Our findings are also similar to the reported autopsy literature in terms of distribution of involvement of vessels. $^{23,24}$ For example, among arterial structures, involvement of the small arterial perforators is reportedly most frequent. In terms of venous involvement, granulomatous phlebitis has been most frequently noted in the paraventricular veins along the lateral and third ventricles. This is similar to our observations where involvement of either or both these vessels was seen in $8 / 14$ cases (57\%). Systemic vasculitis associated with sarcoidosis has been previously reported. ${ }^{25,26}$ More recent sporadic case reports have also noted CNS vasculitis on conventional angiography or VWI, albeit in patients presenting with stroke. ${ }^{27,28}$ Our study, however, documents the extent and distribution of vascular abnormalities in patients with NS without a distinct stroke-like syndrome.

The imaging findings described here are not necessarily specific to NS and may be seen with other intracranial pathologies and vasculitides, although it is possible that when combined with the constellation of other findings (e.g., meningitis, white matter lesions, and cranial nerve involvement), they may be more indicative of NS than primary angiitis of the central nervous system or infectious/ inflammatory vasculitis. The emphasis of the current work is to highlight that these imaging findings in NS exist and are more common than previously recognized.

Finally, given that 9/13 (69\%) patients had some evidence of vascular involvement, our findings would support having a dedicated imaging protocol for patients with NS that can capture these abnormalities. The sequences that we found most useful in the analysis included 3D T1W black-blood fast-spin echo imaging sequences using variable flip-angle refocusing pulse. These are available under different names across vendors, such as SPACE (Siemens, Erlangen, Germany); volume isotropic turbo spin echo acquisition; Philips Healthcare, Best, 
The Netherlands; and CUBE (GE Healthcare, Milwaukee, Wisconsin). ${ }^{13}$ In addition, we used SWI that is again available under different names across vendors (SWI for Siemens; susceptibility-weighted angiography for GE and SWI phase for Philips). Including other routine sequences such as FLAIR, T2WI, and diffusion-weighted imaging, our study protocol had a cumulative time of 30-35 minutes, which is a clinically reasonable time frame and should be easily adaptable in the clinical workflow. An important point is the need for the scans to be acquired at a higher magnet strength (such as $3 \mathrm{~T}$ ), given the requirement for higher spatial resolution.

Limitations of our study include the small sample size and absence of a control group which restricted a more detailed analysis between individual imaging manifestations and clinical features. However, our current work presents a preliminary study evaluating the spectrum of imaging findings in a rare disease. The mean cardiovascular risk factors in our study were 1.3 per patient, and their confounding effects on large vessel enhancement or NEWM remain unaddressed. A prior study previously reported a prevalence of about $39 \%$ for NEWM changes in healthy subjects who had mean cardiovascular risk factors of $1.04 .^{29}$ In addition, because a number of patients were clinically improved and on therapy, the prevalence of PVE on VWI is likely underestimated in the current cohort. PVE has been shown to be significantly associated with cerebrovascular events in NS, and it is possible that their assessment in treatment-naive patients may provide additional insights in the frequency of vascular involvement. ${ }^{4}$ Finally, we used black-blood imaging with a voxel size of $0.63 \mathrm{~mm}^{3}$. Although it provides much better resolution than routine clinical imaging, a voxel size of $0.5 \mathrm{~mm}^{3}$ would be more optimal for flow suppression and vessel wall characterization.

In conclusion, involvement of intracranial arterial and venous vessels in NS is more common than previously considered. Our preliminary work outlines the spectrum of imaging findings and their distribution. It is possible, given the high prevalence, that these findings may be useful in differentiating NS from other neuroinflammatory disorders like multiple sclerosis and neuromyelitis optica spectrum disorders where vascular involvement is not well documented. Finally, our work would support having a dedicated VWI protocol to evaluate patients with NS to better understand the evolution of these findings with therapy.

\section{Acknowledgment}

Some of the patients were scanned as part of an ongoing research study sponsored by the Foundation of Sarcoidosis Research.

\section{Study Funding}

No targeted funding reported.

\section{Disclosure}

G. Bathla: research grants from the Foundation of Sarcoidosis Research, Siemens Healthcare, and American Cancer Society. L. Abdel-Wahed: reports no disclosures. A. Agarwal: paid consultant for Authentic4D. T.A. Cho and S. Gupta: report no disclosures. K.A. Jones: consultant for Audentes Therapeutics, Inc. S. Priya and N. Soni: report no disclosures. B. Wasserman: patent no. 13/922,111; no financial gain.

\section{Publication History}

Received by Neurology: Neuroimmunology \& Neuroinflammation March 9, 2021. Accepted in final form June 28, 2021.

Appendix Authors

\begin{tabular}{|c|c|c|}
\hline Name & Location & Contribution \\
\hline $\begin{array}{l}\text { Girish Bathla, } \\
\text { MBBS, FRCR, } \\
\text { MMeD, DABR }\end{array}$ & $\begin{array}{l}\text { Department of Radiology, } \\
\text { University of Iowa Hospitals } \\
\text { and Clinics, IA }\end{array}$ & $\begin{array}{l}\text { Drafting/revision of the } \\
\text { manuscript for content, } \\
\text { including medical writing } \\
\text { for content; major role in } \\
\text { the acquisition of data; } \\
\text { study concept or design; } \\
\text { and analysis or } \\
\text { interpretation of data }\end{array}$ \\
\hline $\begin{array}{l}\text { Lama Abdel- } \\
\text { Wahed, MD }\end{array}$ & $\begin{array}{l}\text { Department of Neurology, } \\
\text { University of lowa Hospitals } \\
\text { and Clinics, IA }\end{array}$ & $\begin{array}{l}\text { Major role in the acquisition } \\
\text { of data and analysis or } \\
\text { interpretation of data }\end{array}$ \\
\hline $\begin{array}{l}\text { Amit Agarwal, } \\
\text { MD }\end{array}$ & $\begin{array}{l}\text { Department of Radiology, } \\
\text { University of Texas } \\
\text { Southwestern Medical } \\
\text { Center }\end{array}$ & $\begin{array}{l}\text { Drafting/revision of the } \\
\text { manuscript for content, } \\
\text { including medical writing } \\
\text { for content; study concept } \\
\text { or design; and analysis or } \\
\text { interpretation of data }\end{array}$ \\
\hline
\end{tabular}

Tracey A. Cho, Department of Neurology, Drafting/revision of the MD University of lowa Hospitals manuscript for content, and Clinics, IA including medical writing for content; study concept or design; and analysis or interpretation of data

\begin{tabular}{|c|c|c|}
\hline $\begin{array}{l}\text { Sarika Gupta, } \\
\text { MD, FRCP }\end{array}$ & $\begin{array}{l}\text { Department Pathology, } \\
\text { University of lowa Hospitals } \\
\text { and Clinics, IA }\end{array}$ & $\begin{array}{l}\text { Major role in the acquisition } \\
\text { of data and analysis or } \\
\text { interpretation of data }\end{array}$ \\
\hline $\begin{array}{l}\text { Karra A. Jones, } \\
\text { MD }\end{array}$ & $\begin{array}{l}\text { Department Pathology, } \\
\text { University of lowa Hospitals } \\
\text { and Clinics, IA }\end{array}$ & $\begin{array}{l}\text { Drafting/revision of the } \\
\text { manuscript for content, } \\
\text { including medical writing } \\
\text { for content; major role in } \\
\text { the acquisition of data; and } \\
\text { analysis or interpretation of } \\
\text { data }\end{array}$ \\
\hline Sarv Priya, MD & $\begin{array}{l}\text { Department of Radiology, } \\
\text { University of lowa Hospitals } \\
\text { and Clinics, lowa City, IA, } \\
\text { USA }\end{array}$ & $\begin{array}{l}\text { Drafting/revision of the } \\
\text { manuscript for content, } \\
\text { including medical writing } \\
\text { for content, and major role } \\
\text { in the acquisition of data }\end{array}$ \\
\hline $\begin{array}{l}\text { Neetu Soni, } \\
\text { MD, DNB }\end{array}$ & $\begin{array}{l}\text { Department of Radiology, } \\
\text { University of lowa Hospitals } \\
\text { and Clinics, IA }\end{array}$ & $\begin{array}{l}\text { Drafting/revision of the } \\
\text { manuscript for content, } \\
\text { including medical writing } \\
\text { for content, and study } \\
\text { concept or design }\end{array}$ \\
\hline $\begin{array}{l}\text { Bruce A. } \\
\text { Wasserman, } \\
\text { MD }\end{array}$ & $\begin{array}{l}\text { Department of Radiology, } \\
\text { Johns Hopkins School of } \\
\text { Medicine, Baltimore, MD }\end{array}$ & $\begin{array}{l}\text { Drafting/revision of the } \\
\text { manuscript for content, } \\
\text { including medical writing } \\
\text { for content, and analysis or } \\
\text { interpretation of data }\end{array}$ \\
\hline
\end{tabular}

\section{References}

1. Bathla G, Singh AK, Policeni B, Agarwal A, Case B. Imaging of neurosarcoidosis: common, uncommon, and rare. Clin Radiol. 2016;71(1):96-106.

2. Bagnato F, Stern BJ. Neurosarcoidosis: diagnosis, therapy and biomarkers. Expert Rev Neurother. 2015;15(5):533-548. 
3. Fritz D, van de Beek D, Brouwer MC. Clinical features, treatment and outcome in neurosarcoidosis: systematic review and meta-analysis. BMC Neurol. 2016;16(1):220.

4. Bathla G, Watal P, Gupta S, et al. Cerebrovascular manifestations in neurosarcoidosis: how common are they and does perivascular enhancement matter? Clin Radiol. 2018; 73(10):907.e15-907.e923.

5. Bathla G, Watal P, Gupta S, Nagpal P, Mohan S, Moritani T. Cerebrovascular manifestations of neurosarcoidosis: an underrecognized aspect of the imaging spectrum. AJNR Am J Neuroradiol. 2018;39(7):1194-1200.

6. Christoforidis GA, Spickler EM, Recio MV, Mehta BM. MR of CNS sarcoidosis: correlation of imaging features to clinical symptoms and response to treatment. AJNR Am J Neuroradiol. 1999;20(4):655-669.

7. O'Dwyer JP, Al-Moyeed BA, Farrell MA, et al. Neurosarcoidosis-related intracranial haemorrhage: three new cases and a systematic review of the literature. Eur J Neurol. 2013;20(1):71-78.

8. Pawate S, Moses H, Sriram S. Presentations and outcomes of neurosarcoidosis: a study of 54 cases. QJM. 2009;102(7):449-460.

9. Bathla G, Freeman CW, Moritani T, et al. Retrospective, dual-centre review of imaging findings in neurosarcoidosis at presentation: prevalence and imaging sub-types. Clin Radiol. 2020;75(10):796.e1-796.e9.

10. Zamora C, Hung SC, Tomingas C, Atkinson C, Castillo M. Engorgement of deep medullary veins in neurosarcoidosis: a common-yet-underrecognized cerebrovascular finding on SWI. AJNR Am J Neuroradiol. 2018;39(11):2045-2050.

11. Zajicek JP, Scolding NJ, Foster O, et al. Central nervous system sarcoidosis-diagnosis and management. QJM. 1999;92(2):103-117.

12. Stern BJ, Royal W III, Gelfand JM, et al. Definition and consensus diagnostic criteria for neurosarcoidosis: from the neurosarcoidosis consortium consensus group. JAMA Neurol. 2018;75(12):1546-1553.

13. Leao DJ, Agarwal A, Mohan S, Bathla G. Intracranial vessel wall imaging: applications, interpretation, and pitfalls. Clin Radiol. 2020;75(10):730-739.

14. Mandell DM, Mossa-Basha M, Qiao Y, et al. Intracranial vessel wall MRI: principles and expert consensus recommendations of the American society of neuroradiology. AJNR Am J Neuroradiol. 2017;38(2):218-229.

15. Portanova A, Hakakian N, Mikulis DJ, Virmani R, Abdalla WM, Wasserman BA Intracranial vasa vasorum: insights and implications for imaging. Radiology. 2013; 267(3):667-679.

16. Leithner D, Wichmann JL, Mahmoudi S, et al. Diagnostic yield of $90-\mathrm{kVp}$ low-tubevoltage carotid and intracerebral CT-angiography: effects on radiation dose, image quality and diagnostic performance for the detection of carotid stenosis. $\mathrm{Br} J$ Radiol. 2018;91(1086):20170927.

17. Raza N, Schreck KC. Neurosarcoidosis presenting with recurrent strokes: a case report and literature review. Neurohospitalist. 2017;7(2):91-95.

18. Geurts LJ, Zwanenburg JJM, Klijn CJM, Luijten PR, Biessels GJ. Higher pulsatility in cerebral perforating arteries in patients with small vessel disease related stroke, a 7T MRI study. Stroke. 2018;50:62-68.

19. Kang CK, Park CA, Lee $\mathrm{H}$, et al. Hypertension correlates with lenticulostriate arteries visualized by $7 \mathrm{~T}$ magnetic resonance angiography. Hypertension. 2009;54(5): 1050-1056.

20. Ma SJ, Sarabi MS, Yan L, et al. Characterization of lenticulostriate arteries with high resolution black-blood T1-weighted turbo spin echo with variable flip angles at 3 and 7 Tesla. Neuroimage. 2019;199:184-193.

21. Seo SW, Kang CK, Kim SH, et al. Measurements of lenticulostriate arteries using 7T MRI: new imaging markers for subcortical vascular dementia. J Neurol Sci. 2012; 322(1-2):200-205

22. Delaney P. Neurologic manifestations in sarcoidosis: review of the literature, with a report of 23 cases. Ann Intern Med. 1977;87(3):336-345.

23. Herring AB, Urich H. Sarcoidosis of the central nervous system. J Neurol Sci. 1969; 9(3):405-422.

24. Brown MM, Thompson AJ, Wedzicha JA, Swash M. Sarcoidosis presenting with stroke. Stroke. 1989;20(3):400-405.

25. Dalia T, Liu D, Fraga GR, Springer J. A rare case of sarcoidosis presenting with cutaneous medium-vessel granulomatous vasculitis treated with rituximab. J Clin Rheumatol. 2018 Dec 5. doi: 10.1097/RHU.0000000000000941.

26. Harzallah A, Kaaroud H, Boubaker K, et al. Acute kidney injury with granulomatous interstitial nephritis and vasculitis revealing sarcoidosis. Saudi J Kidney Dis Transpl. 2017;28(5):1157-1161

27. Castro PNP, Santos RQD, Machado DC, Schmidt FDR, Moreira DM. Sarcoid vasculitis presenting with stroke: 3D T1 dark blood vessel wall imaging. Arq Neuropsiquiatr. 2019;77(6):447.

28. Macêdo PJ, da Silveira VC, Ramos LT, Nóbrega FR, Vasconcellos LF. Isolated central nervous system vasculitis as a manifestation of neurosarcoidosis. J Stroke Cerebrovasc Dis. 2016;25(6):e89-92.

29. Baum KA, Schulte C, Girke W, Reischies FM, Felix R. Incidental white-matter foci on MRI in "healthy" subjects: evidence of subtle cognitive dysfunction. Neuroradiology. 1996;38(8):755-760. 


\title{
Neurology \\ Neuroimmunology \& Neuroinflammation
}

\author{
Vascular Involvement in Neurosarcoidosis: Early Experiences From Intracranial \\ Vessel Wall Imaging \\ Girish Bathla, Lama Abdel-Wahed, Amit Agarwal, et al. \\ Neurol Neuroimmunol Neuroinflamm 2021;8; \\ DOI 10.1212/NXI.0000000000001063
}

This information is current as of August 4, 2021

\section{Updated Information \& \\ Services \\ References \\ Subspecialty Collections}

Permissions \& Licensing

Reprints including high resolution figures, can be found at:

http://nn.neurology.org/content/8/6/e1063.full.html

This article cites 29 articles, 5 of which you can access for free at: http://nn.neurology.org/content/8/6/e1063.full.html\#\#ref-list-1

This article, along with others on similar topics, appears in the following collection(s):

\section{DWI}

http://nn.neurology.org//cgi/collection/dwi

MRI

http://nn.neurology.org//cgi/collection/mri

Other cerebrovascular disease/ Stroke

http://nn.neurology.org//cgi/collection/other_cerebrovascular_disease_ stroke

$\overline{\text { Vasculitis }}$

http://nn.neurology.org//cgi/collection/vasculitis

Information about reproducing this article in parts (figures,tables) or in its entirety can be found online at:

http://nn.neurology.org/misc/about.xhtml\#permissions

Information about ordering reprints can be found online:

http://nn.neurology.org/misc/addir.xhtml\#reprintsus

Neurol Neuroimmunol Neuroinflamm is an official journal of the American Academy of Neurology.

Published since April 2014, it is an open-access, online-only, continuous publication journal. Copyright

Copyright $\odot 2021$ The Author(s). Published by Wolters Kluwer Health, Inc. on behalf of the American

Academy of Neurology.. All rights reserved. Online ISSN: 2332-7812.

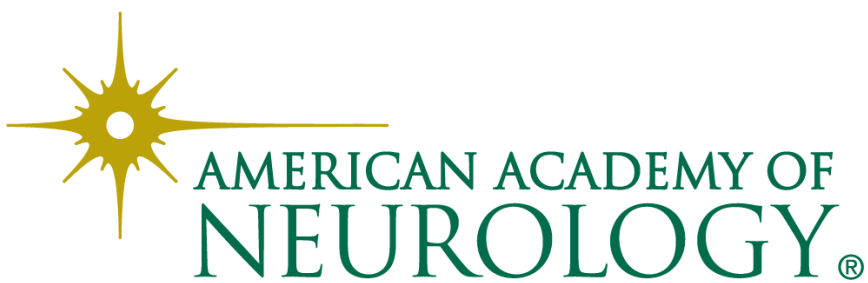

